\title{
National Heart, Lung, and Blood Institute and American Association for Thoracic Surgery Workshop Report: Identifying collaborative clinical research priorities in lung transplantation
}

Michael S. Mulligan, MD, ${ }^{a}$ David Weill, MD, ${ }^{\mathrm{b}}$ R. Duane Davis, MD, ${ }^{\mathrm{c}}$ Jason D. Christie, MD, MSCE, ${ }^{\mathrm{d}}$ Farhood Farjah, MD, MPH, ${ }^{a}$ Jonathan P. Singer, MD, MS, ${ }^{e}$ Matthew Hartwig, MD, ${ }^{f}$ Pablo G. Sanchez, MD, PhD, ${ }^{\mathrm{g}}$ Daniel Kreisel, MD, PhD, ${ }^{\mathrm{h}}$ Lorraine B. Ware, MD, ${ }^{\mathrm{i}}$ Christian Bermudez, MD, Ramsey R. Hachem, MD, ${ }^{\mathrm{k}}$ Michael J. Weyant, MD, ${ }^{1}$ Cynthia Gries, MD, Jeremiah W. Awori Hayanga, MD, MPH, ${ }^{\mathrm{m}}$ Bartley P. Griffith, MD, ${ }^{\mathrm{n}}$ Laurie D. Snyder, MD, Jonah Odim, MD, PhD,${ }^{\mathrm{p}}$ J. Matthew Craig, PhD,${ }^{\mathrm{q}}$ Neil R. Aggarwal, MD,${ }^{\mathrm{q}}$ and Lora A. Reineck, MD, MS

\footnotetext{
From the a Division of Cardiothoracic Surgery, Department of Surgery, University of Washington, Seattle, Wash; ${ }^{\mathrm{b}}$ Weill Consulting Group, New Orleans, La; ${ }^{\mathrm{c}}$ Florida Hospital, Orlando, Fla; ${ }^{\mathrm{d}}$ Division of Pulmonary and Critical Care Medicine, Department of Medicine, and ${ }^{\mathrm{j}}$ Division of Cardiovascular Surgery, Department of Surgery, University of Pennsylvania, Philadelphia, Pa; ${ }^{\mathrm{e} D i v i s i o n}$ of Pulmonary, Critical Care, Allergy and Sleep Medicine, Department of Medicine, University of California San Francisco, San Francisco, Calif; ${ }^{\mathrm{f}}$ Division of Cardiovascular and Thoracic Surgery, Department of Surgery, and ${ }^{\circ}$ Division of Pulmonary, Allergy, and Critical Care Medicine, Department of Medicine, Duke University, Durham, NC; ${ }^{\mathrm{g}}$ Department of Cardiothoracic Surgery, University of Pittsburgh, Pittsburgh, Pa; ${ }^{\mathrm{h}}$ Division of Cardiothoracic Surgery, Department of Surgery, and ${ }^{\mathrm{k}}$ Division of Pulmonary and Critical Care Medicine, Department of Medicine, Washington University, St Louis,

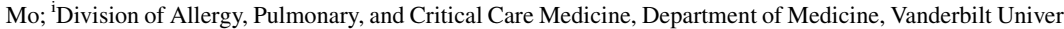
sity Medical Center, Nashville, Tenn; ${ }^{1}$ Division of Cardiothoracic Surgery, Department of Surgery, University of Colorado, Denver, Colo; ${ }^{\mathrm{m}}$ Department of Cardiovascular and Thoracic Surgery, West Virginia University, Morgantown, WVa; ${ }^{\mathrm{n}}$ Division of Cardiac Surgery, Department of Surgery, University of Maryland, Baltimore,

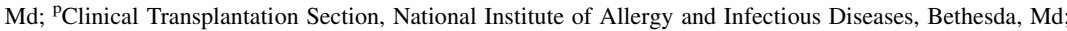
and ${ }^{\mathrm{q}}$ Division of Lung Diseases, National Heart, Lung, and Blood Institute, Bethesda, Md.

This workshop was funded by the National Heart, Lung, and Blood Institute (NHLBI) and the American Association for Thoracic Surgery.

The opinions expressed in this article are those of the authors and do not necessarily represent the US Department of Health and Human Services, the National Institutes of Health, the NHLBI, the National Institute of Allergy and Infectious Diseases, or the Health Resources and Services Administration. The NHLBI logo cannot be used to promote or suggest endorsement of non-NHLBI products, events, or services or to misrepresent the purpose, character, policies, or mission of the NHLBI.

Additional workshop participants: Kevin Chan, MD, University of Michigan; Jeffrey Goldstein, Lung Transplant Foundation; Elisa Gordon, PhD, MPH, Northwestern University; Timothy Whelan, MD, Medical University of South Carolina; Sean Agbor-Enoh, MD, PhD, NHLBI; James Bowman III, MD, Health Resources and Services Administration; James Kiley, PhD, NHLBI; Mark Robien, MD, NIAID; Hannah Valantine, MD, NHLBI; Gail Weinmann, MD, NHLBI

Received for publication June 7, 2018; revisions received Aug 1, 2018; accepted for publication Aug 5, 2018; available ahead of print Sept 20, 2018.

Address for reprints: Lora A. Reineck, MD, MS, Division of Lung Diseases, National Heart, Lung, and Blood Institute, Two Rockledge Centre, Suite 10042, 6701 Rockledge Dr, MSC 7952, Bethesda, MD 20892 (E-mail: lora.reineck@nih.gov).

J Thorac Cardiovasc Surg 2018;156:2355-65

$0022-5223 / \$ 0.00$

Published by Elsevier Inc. on behalf of The American Association for Thoracic Surgery

https://doi.org/10.1016/j.jtcvs.2018.08.010
}

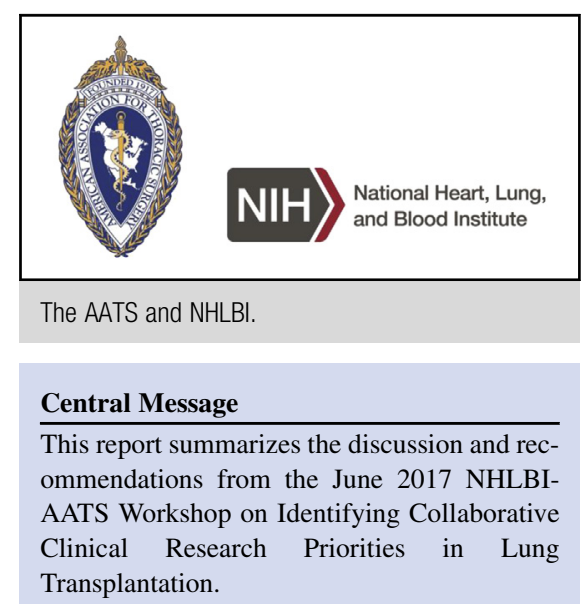

In 2016, more than 2300 lung transplants were performed in the United States, and approximately 2700 candidates were added to the wait-list. ${ }^{1}$ Clinical outcomes after lung transplantation lag behind those achieved with transplantation of other solid organs, with average 5-year survival of $55 \%$. Despite this, lung transplantation is a relatively understudied area of clinical research, and few prospective randomized trials are conducted in lung transplantation. In June 2017, the National Heart, Lung, and Blood Institute (NHLBI) and American Association for Thoracic Surgery (AATS) co-sponsored a workshop designed to bring participants together to summarize the current state of the science in adult lung transplantation, identify knowledge gaps, and determine priorities in clinical lung transplant research that could be addressed in the near future. Workshop topics were initially drafted by the AATS with input from the International Society for Heart and Lung Transplantation (ISHLT), and then finalized by the NHLBI and AATS leadership. Workshop participants included leaders in lung transplantation with specific expertise in thoracic surgery, pulmonary medicine, and bioethics. Although all present acknowledged that chronic lung allograft 
dysfunction (CLAD) is the predominant cause of late mortality and the biggest impediment to long-term success in lung transplantation, this topic was outside the scope of the workshop. The focus of this workshop was the time period from recipient selection to 1 year post-transplant.

Currently available resources for clinical lung transplantation research include the United Network for Organ Sharing (UNOS) database, the ISHLT registry, the National Institute of Allergy and Infectious Diseases-funded Clinical Trials in Organ Transplantation (CTOT), and the NHLBIfunded Lung Transplant Outcomes Group (LTOG). The UNOS and ISHLT databases are large registries that are analyzed frequently to report differences and trends in outcomes and practice patterns. Although UNOS mandates participation in their database, ISHLT registry participation is voluntary. The main strength of these databases is their size. However, reporting is not always current, data may be incomplete, and not all data elements that might affect relevant outcomes are captured. The CTOT and Clinical Trials in Organ Transplantation in Children (CTOT-C) consortia include observational studies and clinical trials involving all solid-organ transplantation, whereas the LTOG is principally focused on observational studies of adult lung primary graft dysfunction (PGD). Several CTOT and CTOT-C studies involve aspects of adult or pediatric lung transplantation, respectively. CTOT-03 was designed to look at inflammatory gene expression signatures present in lung donors and their impact on early outcomes, whereas CTOT-20 and CTOT-22 include prospective multicenter studies to identify predictive risk factors for the development of CLAD and cytomegalovirus infection in adult transplant recipients. CTOT-C includes studies examining viral triggers of alloimmunity and autoimmunity and their impact on outcomes (CTOT-C-03, CTOT-C-14), perceived barriers to patient adherence to immunosuppressive regimens (CTOT-C-05), the efficacy of B-cell-depleting induction therapy with rituximab (CTOT-C-08), and correlates of post-traumatic stress symptoms (CTOT-C-11) in pediatric lung transplant recipients. Data in the LTOG are collected preoperatively from lung donors and recipients, and postoperatively during the first 3 days after transplantation with the focus on understanding risks and mechanisms of PGD.

Workshop topics addressed over the 2-day workshop included recipient selection issues, optimizing the potential donor organ pool, perioperative issues, and strategies to prevent PGD. The topics presented at the workshop are described next with summary recommendations for clinical investigations listed at the end.

\section{RECIPIENT SELECTION}

\section{Defining Transplant Benefit and Who Benefits Most}

Lung transplantation is intended to extend survival, relieve disability, and improve health-related quality of life (HRQL) for adults with end-stage lung disease., ${ }^{2,3}$ Several pretransplant recipient factors that are associated with recipient death or graft failure after transplant surgery have been identified. These include older recipient age, critical illness, extrapulmonary end-organ dysfunction, psychiatric illness, and lack of adequate social support. ${ }^{4}$ How these risk factors interact with transplant program experience, expected wait times, and available expertise is unknown. Therefore, identifying individual candidates who will survive and thrive after lung transplantation is still based largely on clinical judgment.

Lung transplant candidates are older and more critically ill at the time a donor offer is accepted than they have been in the past. The proportion of transplant recipients in the United States who are hospitalized in the intensive care unit before transplantation more than tripled from $3.7 \%$ in 2003 to $14.1 \%$ in 2013,5 and there has been a rapid increase in the number of patients bridged to transplant on mechanical ventilation or extracorporeal life support (ECLS), or both. ${ }^{5,6}$ Performing transplantation in older and more critically ill recipients has not changed overall survival trends, ${ }^{7,8}$ but instead has been associated with substantial cost increases due to greater post-transplant disability, worse HRQL, and decreased survival beyond 1 year. ${ }^{9-13}$ In addition, length of stay, discharge to places other than home, costs, and wait-list mortality are all trending in an undesirable direction. ${ }^{14}$

There is a need to comprehensively redefine transplant benefit. Although 1-year mortality has driven organ allocation policy and represents the standard against which program quality is judged, many patients consider transplantation to improve their HRQL even if a survival advantage is not ensured. As such, transplant benefit should include patient-centered outcomes that are meaningful and important to patients and caregivers. A majority of patientcentered outcome literature in lung transplantation has focused on HRQL; however, these studies have been small to moderate-sized single-center cohorts, many of which were subject to selection and survivorship bias. ${ }^{15}$ There is also a need for clinical prediction tools to identify which candidates will achieve reasonable outcomes and which will not. Because decision-making depends on multiple outcome domains (eg, efficacy, safety, HRQL, and function), multiple models may be needed.

Given the increasing age of transplant candidates, applying concepts and principles from the geriatric literature to lung transplantation may be productive. Incorporation of an operational definition of frailty would also be useful, although there is no current consensus of how best to quantitate frailty. For debilitated and poorly nourished patients, a course of pretransplant rehabilitation designed to modify frailty or alter body composition may potentially improve outcomes, but this has not been proven. ${ }^{16}$ For example, early evidence suggests that weight loss in the 
setting of a structured pretransplant exercise program may reduce the risk of post-transplant death. ${ }^{17}$

Key questions in this area include the following:

- How can transplant benefit be better defined to include patient-centered outcomes and HRQL?

- Does a pretransplant diet, exercise program, or psychosocial preparation regimen improve recipient outcomes, such as survival, functional outcomes, post-transplant discharge location, cost, and HRQL?

- How can lung transplant candidate and recipient risk be quantified and standardized, including the assessment of adiposity, sarcopenia, and frailty?

- What is the impact of lung transplantation on patientcentered outcomes for different recipient characteristics (eg, sex, age, disease category, race/ethnicity)?

\section{Extracorporeal Life Support as a Bridge to Transplant}

Outcomes of patients with decompensated respiratory failure who are bridged to lung transplant using ECLS have historically been poor. ${ }^{18}$ More recent cohorts demonstrate improved survival and suggest better outcomes for ECLS when compared with patients receiving longer durations of mechanical ventilation. ${ }^{19-23}$ Outcomes appear to vary depending on timing of initiation of support, patient status, and mode of support, but early intervention before mechanical ventilation has been associated with improved post-transplant survival compared with transplant recipients who received ECLS after failing mechanical ventilator support. ${ }^{19-24}$ Improved outcomes have also been reported for patients supported by ECLS while awake, ambulatory, and extubated. ${ }^{24,25}$ Likewise, patients who are bridged to transplant on veno-venous ECLS appear to have better outcomes than those bridged with veno-arterial ECLS. ${ }^{23}$ However, the interpretation of many of the studies of ECLS as a bridge to transplant is challenging because of limitations, including selection bias, confounding due to differences in patient characteristics (eg, severity of illness), management of candidates on ECLS (eg, sedation, ambulation), and variable thresholds for initiation of ECLS support between centers.

Under current UNOS policy, patients placed on ECLS have the same lung allocation score as mechanically ventilated patients on $100 \%$ oxygen, regardless of the threshold level of illness that prompted the use of ECLS. Determining the optimal threshold for ECLS support and standardizing the threshold for initiation of ECLS across centers would help ensure equitable allocation of organs.

Empirical data are lacking to support a growing trend in the use of ECLS before conventional support (eg, mechanical ventilation) during acute decompensation of patients awaiting transplantation or to initiate ECLS support in patients who have yet to be evaluated for transplantation. In fact, in one series of 21 patients with interstitial lung disease who decompensated and were supported by ECLS, only 6 underwent transplantation with 5 surviving to hospital discharge. ${ }^{26}$ In addition to the potential impact on organ allocation, this trend may increase healthcare costs. Overall, clarification is needed to determine the criteria for ECLS support and appropriate strategies for support. More clarity would help determine the effect of ECLS on lung transplant outcomes and organ allocation policy.

Key questions in this area include the following:

- Does ECLS, compared with mechanical ventilation alone, result in superior outcomes in decompensating patients listed for lung transplantation?

- In patients who are bridged to transplant with ECLS, what pretransplant factors or recipient characteristics are associated with worse clinical outcomes, including death, withdrawal from the wait-list, and posttransplant complications?

\section{Use of Marginal Donor Lungs}

The definition of what constitutes an ideal donor lung is evolving, and practice patterns regarding the appropriate use of "marginal" donor lungs that do not meet these criteria vary considerably. Original criteria used to characterize ideal donor lungs was based largely on expert opinion. $^{27}$ A 2002 research letter published in Lancet suggested that $41 \%$ of discarded lungs would have been suitable for use as donor lungs, and that the criteria to determine appropriate donor lungs were restrictive and may have hindered donor lung use. ${ }^{28}$ Because the original criteria were challenged by this report, there has been a greater than $40 \%$ increase in lung transplants over the last decade that likely reflects changing opinions on donor suitability.

Donor age as an independent criterion for defining an organ as acceptable has been debated, and there is a trend toward using lungs from older donors. Recent experience with the use of lungs in donors aged more than 70 years does not suggest any significant compromise to post-transplant survival. ${ }^{29}$ However, functional outcomes appeared to be better preserved among recipients receiving transplants for emphysema and not pulmonary fibrosis. ${ }^{29}$

Multiple single-center studies report that approximately half of their donor organs are characterized as marginal. $^{30-34}$ These studies report no difference in outcomes including survival, postoperative ventilator days, oxygenation, or complications, except in some cases in which outcomes were worse in recipients with cystic fibrosis. Some of these reports found that marginal lungs 
are best used in bilateral lung transplantation, although this finding is not consistent across all studies or recipients. A more recent single-center study showed that patients receiving transplants for suppurative lung disease with marginal organs had higher 30 -day mortality $(17 \%$ vs $2 \%)$ and that the use of marginal lungs was associated with a higher rate of grade 3 PGD ( $44 \%$ vs $27 \%$ ). ${ }^{35}$ Data from the UNOS database demonstrate that high-risk recipients may not be good candidates for marginal lungs: Among recipients with a lung allocation score of 70 or greater, the use of marginal lungs was associated with a significant increase in 1year mortality. ${ }^{36}$

There remains a lack of proven, objective criteria with which to assess acceptability of donor lungs. Various scoring methodologies have been proposed, but none have been widely adopted. Further research is needed to better inform clinical decision-making regarding donor characteristics that define a suitable lung allograft and which lung transplant candidates are most appropriate to receive "marginal" donor lungs.

Key questions in this area include the following:

- How should "marginal" donor lungs be objectively defined to more accurately inform clinical decision making?

- Which recipients are the most appropriate for the use of "marginal" lungs?

\section{OPTIMIZING THE POTENTIAL DONOR ORGAN POOL \\ Variability in Organ Acceptance Rates}

Organ acceptance rates vary considerably across centers in part because of lack of consensus about what constitutes an acceptable donor lung. Although most members of the US lung transplant community would embrace a revision of donor acceptance criteria, this effort remains hampered by many factors including a lack of donor infrastructure, risk aversion, liability concerns, and public opinion. Proper assessment of donor lung appropriateness requires a fastidious in-person examination to corroborate or disprove imaging and laboratory data. Development of a donor score, including clinical and radiographic data derived from the procurement site, as well as additional laboratory data obtained after standardized maneuvers in the operating room, would likely be helpful. If widely adopted, a standardized assessment approach offers the potential to significantly increase donor lung utilization rates without sacrificing quality.

Variation in donor hospital performance and practice, as well as Organ Procurement Organization (OPO) management strategies, make it even more important for on-site assessment. However, broad geographic distribution of donor hospitals and limitations in personnel make on-site assessment a costly and judiciously applied practice. A movement toward more centralized donor management centers may increase the ability for specifically trained surgeons and other medical personnel to evaluate and procure a greater number of organs. ${ }^{37}$

Regulatory and societal pressures may also affect donor use, especially among high-risk recipients or for donor lungs deemed to be marginal or meeting extended criteria. For example, transplant centers may at times restrict recipient and donor selection to improve performance on program-specific reports, but this conservative behavior decreases access for certain high-risk transplant recipient groups and may also limit overall donor utilization rates. ${ }^{38}$ Patient awareness, public opinion, and fear of legal action may also hinder the use of extended criteria donors. For example, existing data demonstrate the overall societal survival benefit of using smoking donors for lung transplantation. ${ }^{39}$ However, public awareness of the modest reduction in individual post-transplant outcomes has deterred the use of these donors, and as a result, the rate of utilization in the United States of lungs from donors who have smoked has decreased..$^{5}$

Key questions in this area include the following:

- What are the barriers and facilitators to lung allograft acceptance for each of the involved stakeholders (eg, OPO, donor center, transplant center)?

- Is standardized intraoperative donor assessment more predictive of recipient outcomes than preprocurement assessment?

- Are centralized donor centers feasible and able to increase the number of donor lungs procured and transplanted without compromising recipient outcomes?

\section{The Role for Ex Vivo Lung Perfusion}

Ex vivo lung perfusion (EVLP) was introduced as a donor lung assessment tool in $2001 .^{40}$ It was later used to reassess extended criteria donor lungs. Furthermore, EVLP has been shown to be efficacious in improving the oxygenation of donor lungs rejected for transplantation because of poor oxygenation. ${ }^{41}$ More recently, 2 clinical trials demonstrated the feasibility of transplanting extended criteria donor lungs after EVLP with good clinical outcomes. ${ }^{42,43}$

Using EVLP as a standard assessment tool to obtain data under reproducible conditions may be a useful strategy in overcoming the clinical variability in OPO management and could also expand the donor pool by allowing for higher-fidelity reassessment of extended criteria organs. However, the current EVLP paradigm has limitations. 
For example, the current ventilatory and perfusion modalities are not physiologic in that they use significant ventilator recruitment strategies and low perfusion pressure. Therefore, EVLP platforms used in the United States may benefit from revision to achieve more physiologic assessments.

EVLP also has the potential as a therapeutic platform for novel therapeutic interventions. Transfection technologies and other treatment paradigms could be used ex vivo, whereas use of these strategies in the intact donor might be too costly, cumbersome, and impractical, or have effects on other organs that need to be considered. Defining which therapeutic interventions are most appropriate for use in the EVLP platform could represent a significant role for this technology in the future.

Key questions in this area include the following:

- Does use of EVLP as a standardized assessment tool to evaluate donor lung quality improve donor lung utilization rates and recipient outcomes?

- How can novel therapies for donor lung reconditioning using EVLP platforms be implemented to improve donor lung utilization rates and recipient outcomes?

\section{Donor Lung Procurement}

Most donor lungs in the United States are procured from donation after brain death (DBD) donors, with a minority of donor lungs procured from controlled donation after circulatory death (DCD) donors. DCD donation involves a planned withdrawal of life support in patients who do not meet criteria for brain death. Most studies have demonstrated that short- and long-term outcomes after transplantation of DCD lungs are comparable to those after transplantation of DBD lungs. ${ }^{44,45}$ Despite compelling evidence that DCD lungs can be safely transplanted, such organs are infrequently used in the United States. Limitations in the use of DCD organs stem from ethical, financial, and logistic considerations, as well as lack of awareness of initial studies demonstrating DCD donor lung comparability to DBD donors. ${ }^{46}$ Some transplant programs may be reluctant to consider DCD organs in part because of risk aversion, lack of institutional resources, and limited lung transplant experience. However, more widespread and standardized use of DCD organs could significantly improve donor organ availability and increase transplant rates across the country.

At the present time, OPO practice patterns vary widely with respect to diagnostic and therapeutic interventions that are used to facilitate DCD organ placement. Although some centers decline any intervention that does not directly benefit the potential donor, a multi-society consensus statement recommends that "ante mortem interventions are ethically appropriate if they contribute to good transplant outcomes and have a low chance of harming the prospective donor." 47 As such, diagnostic studies such as computed tomography scans and bronchoscopy can be performed similarly to what occurs in DBD donors, and transplant team representatives can advise OPO personnel regarding appropriate management that can optimize organ function. Studies to define the best strategies and techniques for donor lung procurement are needed.

Key questions in this area include the following:

- What are the barriers and facilitators to DCD and DBD donor lung procurement for each of the involved stakeholders (eg, donor hospital, OPO, transplant center)?

- Will a structured collaborative intervention with OPOs and donor hospitals result in an increase in DCD and DBD lungs being offered and procured?

\section{Optimizing Donor Management Strategies}

Current donor management strategies to optimize organ function vary widely across OPOs and transplant centers. Such strategies are based primarily on physiologic rationale, anecdotal experience, and retrospective clinical studies. For example, the San Antonio Lung Transplant protocol for management of potential lung donors involves OPO education and training, active donor management by transplant pulmonologists, aspiration prevention strategies, maintenance of negative fluid balance, and periods of recruitment using mechanical ventilation with high inspiratory and expiratory pressures. ${ }^{48}$ Use of the San Antonio Lung Transplant protocol demonstrated increased organ utilization rates with no adverse impact on recipient 30day or 1-year outcomes. Similar investigations have been conducted in Europe, but the impact of the overall protocol or specific interventions within the protocol is not known. Furthermore, it is unknown if such interventions would be effective if implemented across all OPOs.

Few randomized clinical trials have been conducted in lung donor management. One of the first assessed the effect of nebulized albuterol versus placebo in lung donors designed to promote resolution of pulmonary edema. ${ }^{49}$ Albuterol treatment did not affect donor oxygenation or donor lung use. Another randomized clinical trial compared 2 different mechanical ventilator protocols in European lung donors. ${ }^{50}$ Donors were randomized to conventional mechanical ventilation or ventilation with low tidal volume and higher positive end-expiratory pressure for 6 hours. Both lung function and subsequent lung use were significantly better in the low tidal volume arm; however, the intervention occurred early in the donor management protocol and lasted only for 6 hours. Current trials include one 
comparing naloxone with placebo for donors with hypoxemia (NCT02581111) and another investigating an open lung protective ventilation strategy in potential lung donors (NCT03439995).

Regulatory issues, especially regarding recipient consent, the current delivery of care model, a general lack of standardized approaches to donor management, and widely distributed donor populations, make clinical trial organization and execution in this area challenging. ${ }^{51}$ Recognizing these complexities, a recent National Academies of Sciences, Engineering, and Medicine consensus study sought to parse the existing barriers and identify opportunities for conducting organ donor intervention research. ${ }^{52}$ Through this report, the committee recommended that donor research stakeholders coordinate to develop resources that effectively communicate information about donor intervention research to the public, improve coordination among agencies around a single national donor registry, provide legal guidance for interventional research involving organ donation, outline the parameters for informed consent to participate in organ donation intervention research, and establish a centralized donor research oversight committee. It is with this framework that we consider research opportunities to optimize the potential donor organ pool with the appreciation that the field of donor management is ripe for clinical investigation with appropriately structured studies.

Key questions in this area include the following:

- What is the optimal recipient consent strategy for donorspecific interventional studies?

- What donor management strategies can improve donor lung utilization rates while preserving or improving recipient outcomes?

\section{PERIOPERATIVE ISSUES \\ Surgical Technique}

Most US lung transplant recipients undergo bilateral lung transplantation. The most common incision used for bilateral lung transplantation is a fourth interspace bilateral thoracosternotomy. However, the morbidity, long-term patient satisfaction, and effect on graft function of the bilateral thoracosternotomy compared with other incisions is unknown. Some centers have espoused the use of more limited access incisions with some single-center reports supporting these approaches; however, definitive comparative outcomes studies based on incisional approach are lacking.

Extracorporeal support may be necessary during lung transplantation; however, the relative benefits of cardiopulmonary bypass (CPB) versus other forms of ECLS are not understood. Best practices are often developed within an institution and then shared anecdotally or informally.
Studies to determine the best mode of extracorporeal support could help provide evidence to inform clinical practice.

Key questions in this area include the following:

- What is the effect of different incisional approaches on recipient outcomes?

- Are recipient outcomes improved with intraoperative ECLS compared with CPB support?

\section{Single Versus Bilateral Lung Transplantation}

Over the last 15 years, there has been a significant growth in the number of double lung transplants performed, whereas the number of single lung transplants performed annually has remained relatively stable. ${ }^{53}$ Double lung transplantation (DLT) is favored for patients with cystic fibrosis, other forms of suppurative lung disease, and group 1 pulmonary arterial hypertension. Patients with a high lung allocation score and those requiring ECLS as a bridge to transplant both appear to have better survival after DLT. ${ }^{54}$ However, there is variability among centers regarding the use of single or DLT, particularly for patients with chronic obstructive pulmonary disease and interstitial lung disease.

Although direct comparison studies report a survival advantage for double versus single lung transplant, the groups are not age or disease matched because the double lung transplant cohort includes a larger number of younger patients who undergo transplant because of underlying cystic fibrosis or pulmonary hypertension. ${ }^{53-56}$ There may be subgroups of recipients who do not benefit from DLT. For example, older patients are at risk for morbidity and potential mortality related to "too much surgery" with a bilateral procedure. As such, older patients are more frequently considered for single lung transplantation. ${ }^{53,54}$ The data are mixed in patients with idiopathic pulmonary fibrosis (IPF). According to the UNOS registry, similar graft survival was noted in IPF recipients concurrently listed for DLT and SLT between 2001 and 2009. ${ }^{57}$ However, a more recent study post-lung allocation score noted a longer median time to graft failure in patients with IPF who received a DLT when compared with those who received an $\mathrm{SLT}{ }^{58}$ Furthermore, in the same study, it was noted that although patients who undergo DLT for emphysema typically note improved function compared with their single lung recipient counterparts, the impact on survival is less clear. ${ }^{58}$ Increased use of single lung transplants may increase the availability of donor lungs for other candidates and therefore increase the net benefit associated with these donors. ${ }^{58-60}$

Literature regarding the optimal procedure in lung retransplantation is scarce. Many centers cite a failing graft as a source of significant morbidity, but research has not 
shown a clear difference in graft or patient survival between recipients of retransplant with single or double lungs when stratified by previous single or DLT. ${ }^{61}$ At present, this would suggest that single lung retransplantation should be considered in these cases regardless of previous transplant type, because this has not been shown to worsen outcomes and it would positively affect organ availability for the waitlist population.

A key question in this area is the following:

- Which lung transplant candidates are best suited for single lung transplantation?

\section{Perioperative Critical Care Management}

There is a dearth of high-quality evidence to guide perioperative critical care management after lung transplantation. Current practices are based on institutional protocols or expert opinion with wide intercenter variability. Significant interest exists in gaining clarity regarding the best strategies for mechanical ventilation, fluid and hemodynamic management, sedation, and use of ECLS after transplantation.

Currently, no randomized controlled trial data exist to guide ventilator management after uncomplicated lung transplantation or in the setting of PGD. The NHLBI acute respiratory distress syndrome (ARDS) network demonstrated the efficacy of lung protective ventilation strategies in ARDS, yet it is unknown how these beneficial strategies may affect the incidence of PGD and longer-term outcomes after lung transplantation. ${ }^{62}$ A single-center study demonstrated a reduction in the incidence of PGD with implementation of an evidence-based protocol for ventilator and hemodynamic management; however, no differences in duration of mechanical ventilation or survival were noted. ${ }^{63}$ Furthermore, although lung protective ventilation strategies are commonly used after transplantation, tidal volumes are often set on the basis of recipient ideal body weight (IBW) as opposed to donor IBW. ${ }^{64}$ Donor characteristics do not appear to be considered by clinicians managing the recipient's ventilatory support. ${ }^{64}$ Concerns about airway anastomotic ischemia have led to a general reluctance in perioperative transplant management to the use of higher levels of positive end-expiratory pressure advocated in ARDS.

A restrictive fluid management strategy is commonly used after lung transplantation to limit pulmonary edema resulting from increased pulmonary vascular permeability. Although this approach has been demonstrated to be effective in reducing duration of mechanical ventilation in patients with ARDS, trials in lung transplantation have not been conducted. ${ }^{65}$ Instead, data are limited to retrospective studies suggesting that increased intraoperative fluid administration and that the use of colloid fluids are associated with an increased risk for PGD, prolonged mechanical ventilation, and mortality. ${ }^{66,67}$
Current data and practice guidelines surrounding the management of sedation in the intensive care unit recommend light sedation to minimize the duration of mechanical ventilation and the incidence of delirium. ${ }^{68}$ However, data in lung transplantation are limited to surveys in which most respondents report that they do not have or follow a formal sedation policy specifically relevant to lung transplant recipients. ${ }^{69}$

The use of ECLS support in the post-transplant setting also varies considerably. Although excellent clinical outcomes can be achieved with ECLS support, thresholds for initiating support vary from institution to institution. Some centers use ECLS based on the theory that by providing complete cardiopulmonary support that bypasses the lungs and obviates the need for ventilator support, the avoidance of ventilator-induced lung injury can expedite lung recovery. However, limited data exist to support this approach, and the optimal clinical scenario where postoperative ECLS may be most beneficial is unknown.

Key questions in this area include the following:

- Does the use of donor compared with recipient IBW to determine post-transplant ventilator settings reduce the risk of ventilator-induced lung injury and PGD?

- What is the impact of protocolized perioperative management, including lung protective ventilation strategies and early implementation of ECLS for PGD, on lung transplant outcomes?

\section{PRIMARY GRAFT DYSFUNCTION Risk Factors and Mechanisms for Primary Graft Dysfunction}

The ISHLT grading system for PGD is summarized in Table 1. The incidence of PGD is between $10 \%$ and $25 \%$, with high 30 -day attributable mortality. ${ }^{70-75}$ Grade 3 PGD is associated with $23 \%$ 90-day and $34 \%$ 1-year mortality, compared with $5 \%$ and $11 \%$, respectively, in those without PGD. ${ }^{76}$ PGD survivors have increased longterm mortality and an increased risk of CLAD. ${ }^{74,75,77,78}$ Furthermore, survivors of PGD have substantial long-term functional impairments. ${ }^{79}$ Thus far, there are no therapeutic agents that prevent or treat PGD. Therefore, any intervention that successfully reduces the risk and severity of PGD could dramatically improve transplant outcomes.

Recipient-related independent risk factors for PGD include a body mass index greater than 25 ; preoperative diagnosis of IPF, sarcoidosis, or pulmonary arterial hypertension; and elevated mean pulmonary artery pressure. ${ }^{71,76,80,81}$ Any donor smoking history is an independent risk factor among donor variables; however, this variable has a need for more accurate quantification. Although there are differences in PGD incidence by 
TABLE 1. International Society for Heart and Lung Transplantation grading of primary graft dysfunction

\begin{tabular}{ccc}
\hline Grade & $\begin{array}{c}\text { Pulmonary edema } \\
\text { on chest X-ray }\end{array}$ & $\mathbf{P a o}_{\mathbf{2}} / \mathbf{F i o} \mathbf{2}$ \\
\hline PGD grade 0 & No & $>300$ \\
PGD grade 1 & Yes & $>300$ \\
PGD grade 2 & Yes & $200-300$ \\
PGD grade 3 & Yes & $<200$ \\
\hline
\end{tabular}

$\mathrm{Fio}_{2}$, Fraction of inspired oxygen; $\mathrm{PaO}_{2}$, partial pressure of oxygen in arterial blood; $P G D$, primary graft dysfunction. Reprinted with permission from Snell GI, Yusen RD, Weill D, Strueber M, Garrity E, Reed A, et al. Report of the ISHLT working group on primary lung graft dysfunction, part I: definition and grading-a 2016 consensus group statement of the International Society for Heart and Lung Transplantation. J Heart Lung Transplant. 2017;36:1097-103.

center, these donor and recipient risk factors are independent of center effects. ${ }^{76}$

Understanding the mechanisms of PGD is a current area of active research. Protein biomarker and genomic studies performed in humans have implicated mechanisms for PGD development similar to those seen in model systems, notably donor cellular injury, innate immune activation, and inflammatory mechanisms. ${ }^{82}$ Likewise, gene expression studies have implicated innate immune and inflammasome activation in the lung and the recipient immune cell response. ${ }^{83}$ Such changes persist in the days after organ reperfusion. ${ }^{84}$ Quantification of markers of such biological processes may serve to enhance the clinical PGD definition, develop syndrome endotypes, and promote discovery of new mechanisms in human studies.

Key questions in this area include the following:

- What therapies can prevent or treat PGD?

- What is the impact of precision interventions based on donor or recipient endotypes on the incidence and severity of PGD?

- Can donor and recipient risk factors (eg, donor smoking exposure) be better quantified to predict PGD?

\section{Preservation, Storage, and Reperfusion Techniques to Prevent Primary Graft Dysfunction}

Initial perfusion solutions consisted of high potassium, low sodium content that replicated the electrolyte and osmotic composition of the intracellular environment. However, because of concerns regarding pulmonary vasoconstriction from the high potassium content, solutions replicating the extracellular environment were studied and found to be superior in terms of prevention of severe graft dysfunction early after transplant. ${ }^{85-87}$

Initial organ preservation began with core cooling to $13^{\circ} \mathrm{C}$ to $15^{\circ} \mathrm{C}$ using $\mathrm{CPB}$, followed by organ removal and storage at $4^{\circ} \mathrm{C}$ using saline and ice. Subsequently, the majority of transplant centers worldwide moved to a single pulmonary artery antegrade flush and topical cooling as the initial step in lung preservation. However, antegrade flushing was recognized to have potential drawbacks. Retrograde pulmonary venous flushing was introduced with the proposed theoretic advantages of being able to clear emboli from the lungs and perfuse the bronchial circulation that is not perfused with antegrade pulmonary arterial delivery. Retrograde flushing has been suggested to reduce the incidence and severity of PGD, and this technique has been adopted by most transplant centers. ${ }^{88,89}$

The technique of reperfusion and composition of the reperfusate may also influence early graft function after transplantation. A technique of controlled reperfusion (ie, gradual pulmonary arterial unclamping over a 10-minute period) has been reported to have a favorable impact on early graft function. ${ }^{90}$ Controlled reperfusion may also be augmented by the intraoperative use of ECLS or CPB.

A key question in this area is the following:

- What preservation, storage, and reperfusion techniques are most effective at preventing or reducing the severity of PGD?

\section{RECOMMENDATIONS FOR FUTURE CLINICAL INVESTIGATION}

Identify donor or recipient interventions that improve survival, as well as functional status and quality of life, after lung transplantation.

- Develop novel precision therapies based on donor or recipient endotypes to prevent PGD and thereby potentially influence the risk of CLAD.

- Assess outcomes in addition to mortality. HRQL, functional status, and validated surrogate end points should be used in lung transplant clinical studies.

- Determine the optimal use and criteria for initiation of ECLS in decompensating patients on the lung transplant waitlist.

Develop improved donor and recipient assessment methods that can be used to better characterize donor-recipient interactions, expand the donor pool, and improve recipient outcomes.

- Establish protocols for standardized intraoperative donor assessment, the collection and bio-banking of accepted and rejected donor tissues, and the quality/type of data collected within transplant registries across treatment centers.

- Design structured interventions with OPOs and donor hospitals to increase the number of successful donations after brain and circulatory death.

- Develop donor and recipient risk scores to help guide donor-recipient selection decisions. 
- Establish core management behaviors (pharmacologic, ventilation strategy, fluid management) that can be investigated for comparative efficacy and serve as evidence-based elements of donor management.

\section{Evaluate surgical approaches and perioperative clinical management strategies to optimize lung transplant recipient outcomes.}

- Determine the impact of routine ECLS compared with standard mechanical ventilation and CPB techniques on lung transplant outcomes.

- Assess if certain types of lung transplant candidates may be best suited for a specific operative procedure such a single versus bilateral lung transplantation or a specific incision type.

- Optimize perioperative critical care of lung transplant recipients including the use of lung protective ventilation strategies.

\section{Conflict of Interest Statement}

M.S.M. is a consultant for Covidien/Medtronic and a Data and Safety Monitoring Board member for Perfusix. J.D.C. receives institutional research grant funding from GlaxoSmithKline and Bristol-Myers Squibb. M.H. is an investigator for Lung Bioengineering and Transmedics clinical trials, and a consultant for Mallinckrodt Pharmaceuticals. D.K. is a member of the scientific advisory board for Compass Therapeutics, receives research grant funding from Compass Therapeutics, and has a patent pending for "Compositions and Methods for Detecting CCR2 Receptors." L.B.W. receives research contract funding from Boehringer Ingelheim and Global Blood Therapeutics, and is on the advisory board for CSL Behring and Bayer. R.R.H. is on the advisory board for Therakos, Theravance, and Vectura, and receives research funding from Therakos. M.J.W. is an educator and consultant for Medtronic. All other authors have nothing to disclose.

\section{References}

1. Valpour M, Lehr CJ, Skeans MA, Smith JM, Carrico R, Uccellini K, et al. OPTN/SRTR 2016 annual data report: lung. Am J Transplant. 2018;18(Suppl 1): 363-433.

2. Valapour M, Skeans MA, Heubner BM, Smith JM, Schnitzler MA, Hertz MI, et al. OPTN/SRTR 2012 annual data report: lung. Am J Transplant. 2014; 14(Suppl 1):139-65.

3. Klein AS, Messersmith EE, Ratner LE, Kochik R, Baliga PK, Ojo AO. Organ donation and utilization in the United States, 1999-2008. Am J Transplant. 2010;10:973-86.

4. Weill D, Benden C, Corris PA, Dark JH, Davis RD, Keshavjee S, et al. A consensus document for the selection of lung transplant candidates: 2014 - an update from the pulmonary transplantation council of the International Society for Heart and Lung Transplantation. J Heart Lung Transplant. 2015;34:1-15.

5. Valapour M, Skeans MA, Heubner BM, Smith JM, Hertz MI, Edwards LB, et al. OPTN/SRTR 2013 annual data report: lung. Am J Transplant. 2015;15(Suppl 2): $1-28$.

6. Valapour M, Paulson K, Smith JM, Hertz MI, Skeans MA, Heubner BM, et al. OPTN/SRTR 2011 annual data report: lung. Am J Transplant. 2013; 13(Suppl 1):149-77.
7. Scientific Registry of Transplant Recipients. Program Specific Reports. Available at: https://www.srtr.org/reports-tools/program-specific-reports/. Accessed June 7, 2017.

8. Yusen RD, Edwards LB, Dipchand AI, Goldfarb SB, Kucheryavaya AY, Levvey BJ, et al. The registry of the International Society for Heart and Lung Transplantation: thirty-third adult lung and heart-lung transplant report - 2016; focus theme: primary diagnostic indications for transplant. J Heart Lung Transplant. 2016;35:1170-84.

9. Genao L, Whitson HE, Zaas D, Sanders LL, Schmader KE. Functional status after lung transplantation in older adults in the post-allocation score era. Am J Transplant. 2013;13:157-66.

10. Maxwell BG, Levitt JE, Goldstein BA, Mooney JJ, Nicolls MR, Zamora M, et al Impact of the lung allocation score on survival beyond 1 year. Am J Transplant. 2014; $14: 2288-94$.

11. Maxwell BG, Mooney JJ, Lee PH, Levitt JE, Chhatwani L, Nicolls MR, et al Increased resource use in lung transplant admissions in the lung allocation score era. Am J Respir Crit Care Med. 2015;191:302-8.

12. Singer LG, Chowdhury N, Faughnan ME, Granton J, Keshavjee S, Marras TK, et al. Effects of recipient age and diagnosis on health-related quality-of-life benefit of lung transplantation. Am J Respir Crit Care Med. 2015;192:965-73.

13. Yusen RD, Edwards LB, Kucheryavaya AY, Benden C, Dipchand AI, Dobbels F, et al. The registry of the International Society for Heart and Lung Transplantation: thirty-first adult lung and heart-lung transplant report - 2014; focus theme: retransplantation. J Heart Lung Transplant. 2014;33:1009-24.

14. Bentley TS. 2014. U.S. organ and tissue transplant cost estimates and discussion. Milliman, Inc. Available at: http://www.milliman.com/uploadedFiles/insight/ Research/health-rr/1938HDP_20141230.pdf. Accessed June 7, 2017.

15. Singer JP, Chen J, Blanc PD, Leard LE, Kukreja J, Chen H. A thematic analysis of quality of life in lung transplant: the existing evidence and implications for future directions. Am J Transplant. 2013;13:839-50.

16. Singer JP, Soong A, Bruun A, Bracha A, Chin G, Hays SR, et al. A mobile health technology enabled home-based intervention to treat frailty in adult lung transplant candidates: a pilot study. Clin Transplant. 2018;e13274.

17. Clausen ES, Frankel CW, Palmer SM, Smith PJ. Change in body mass index (BMI) and mortality following lung transplantation. Am J Respir Crit Care Med. 2017;195:A4644.

18. Mason DP, Thuita L, Nowicki ER, Murthy SC, Pettersson GB, Blackstone EH Should lung transplantation be performed for patients on mechanical respiratory support? The US experience. J Thorac Cardiovasc Surg. 2010;139:765-73.

19. Haneya A, Philipp A, Mueller T, Lubnow M, Pfeifer M, Zink W, et al. Extracorporeal circulatory systems as a bridge to lung transplantation at remote transplant centers. Ann Thorac Surg. 2011;91:250-5.

20. Christie JD, Edwards LB, Aurora P, Dobbels F, Kirk R, Rahmel AO, et al. The registry of the International Society for Heart and Lung Transplantation: twenty-sixth official adult lung and heart-lung transplantation report - 2009. J Heart Lung Transplant. 2009;28:1031-49.

21. de Perrot M, Granton JT, McRae K, Cypel M, Pierre A, Waddell TK, et al. Impact of extracorporeal life support on outcome in patients with idiopathic pulmonary arterial hypertension awaiting lung transplantation. J Heart Lung Transplant. 2011;30:997-1002

22. Hämmäinen P, Schersten H, Lemstrom K, Riise GC, Kukkonen S, Sward K, et al. Usefulness of extracorporeal membrane oxygenation as a bridge to lung transplantation: a descriptive study. J Heart Lung Transplant. 2011;30:103-7.

23. Brogan TV, Thiagarajan RR, Rycus PT, Bartlett RH, Bratton SL. Extracorporeal membrane oxygenation in adults with severe respiratory failure: a multi-center database. Intensive Care Med. 2009;35:2105-14.

24. Fuehner T, Kuehn C, Hadem J, Wiesner O, Gottlieb J, Tudorache I, et al. Extracorporeal membrane oxygenation in awake patients as bridge to lung transplantation. Am J Respir Crit Care Med. 2012;185:763-8.

25. Hartwig MG, Zanotti G, Rehder K, Turner DA, Lin SS, Davis RD. Ambulatory ECMO provides a superior bridge to lung transplantation compared to conventional ECMO. J Heart Lung Transplant. 2012;31:S59.

26. Trudzinski FC, Kaestner F, Schäfers HJ, Fähndrich S, Seiler F, Bohmer P, et al. Outcome of patients with interstitial lung disease treated with extracorporeal membrane oxygenation for acute respiratory failure. Am J Respir Crit Care Med. 2016;193:527-33.

27. Sundaresan S, Trachiotis GD, Aoe M, Patterson GA, Cooper JD. Donor lung procurement: assessment and operative technique. Ann Thorac Surg. 1993;56:1409-13.

28. Ware LB, Wang Y, Fang X, Warnock M, Sakuma T, Hall TS, et al. Assessment of lungs rejected for transplantation and implications for donor selection. Lancet. 2002;360:619-20. 
29. Sommer W, Ius F, Salman J, Avsar M, Tudorache I, Kühn C, et al. Survival and spirometry outcomes after lung transplantation from donors aged 70 years and older. J Heart Lung Transplant. 2015;34:1325-33.

30. Sundaresan S, Semenkovich J, Ochoa L, Richardson G, Trulock EP, Cooper JD, et al. Successful outcome of lung transplantation is not compromised by the use of marginal donor lungs. J Thorac Cardiovasc Surg. 1995;109:1075-9.

31. Meyers BF, Lynch J, Trulock EP, Guthrie TJ, Cooper JD, Patterson GA. Lung transplantation: a decade of experience. Ann Surg. 1999;230:362-70.

32. Gabbay E, Williams TJ, Griffiths AP, Macfarlane LM, Kotsimbos TC, Esmore DS, et al. Maximizing the utilization of donor organs offered for lung transplantation. Am J Respir Crit Care Med. 1999;160:265-71.

33. Bhorade SM, Vigneswaran W, McCabe MA, Garrity ER. Liberalization of donor criteria may expand the donor pool without adverse consequence in lung transplantation. J Heart Lung Transplant. 2000;19:1199-204.

34. Pierre AF, Sekine Y, Hutcheon MA, Waddell TK, Keshavjee SH. Marginal donor lungs: a reassessment. J Thorac Cardiovasc Surg. 2002;123:421-7.

35. Botha P, Trivedi D, Weir CJ, Searl CP, Corris PA, Dark JH, et al. Extended donor criteria in lung transplantation: impact on organ allocation. J Thorac Cardiovasc Surg. 2006;131:1154-60.

36. Mulligan MJ, Sanchez PG, Evans CF, Wang Y, Kon ZN, Rajagopal K, et al. The use of extended criteria donors decreases one-year survival in high-risk lung recipients: a review of the united network of organ sharing database. J Thorac Cardiovasc Surg. 2016;152:891-8.

37. Doyle MBM, Vachharajani N, Wellen JR, Lowell JA, Shenoy S, Ridolfi G, et al. A novel organ donor facility: a decade of experience with liver donors. Am J Transplant. 2014;14:615-20.

38. VanWagner LB, Skaro AI. Program-specific reports: implications and impact on program behavior. Curr Opin Organ Transplant. 2013;18:210-5.

39. Bonser RS, Taylor R, Collett D, Thomas HL, Dark JH, Neuberger J. Effect of donor smoking on survival after lung transplantation: a cohort study of a prospective registry. Lancet. 2012;380:747-55.

40. Steen S, Sjoberg T, Pierre L, Liao Q, Eriksson L, Algotsson L. Transplantation of lungs from a non-heart-beating donor. Lancet. 2001;357:825-9.

41. Wierup P, Haraldsson A, Nilsson F, Pierre L, Schersten H, Silverborn M, et al. Ex vivo evaluation of nonacceptable donor lungs. Ann Thorac Surg. 2006;81:460-6.

42. Cypel M, Yeung JC, Liu M, Anraku M, Chen F, Karolak W, et al. Normothermic ex vivo lung perfusion in clinical lung transplantation. N Engl J Med. 2011;364: $1431-40$.

43. Sanchez PG, Davis RD, D’Ovidio F, Cantu E, Weyant M, Camp P, et al. The NOVEL lung trial one-year outcomes. J Heart Lung Transplant. 2014;33:S71-2.

44. Krutsinger D, Reed RM, Blevins A, Puri V, De Oliveira NC, Zych B, et al. Lung transplantation from donation after cardiocirculatory death: a systematic review and meta-analysis. J Heart Lung Transplant. 2015;34:675-84.

45. Cypel M, Levvey B, Van Raemdonck D, Erasmus M, Dark J, Love R, et al. International Society for Heart and Lung Transplantation donation after circulatory death registry report. J Heart Lung Transplant. 2015;34:1278-82.

46. Cypel M, Levvey B, Van Raemdonck D, Erasmus M, Dark J, Mason D, et al. Lung transplantation using controlled donation after circulatory death donors: trials and tribulations. J Heart Lung Transplant. 2016;35:146-7.

47. Gries CJ, White DB, Truog RD, Dubois J, Cosio CC, Dhanani S, et al. An official American Thoracic Society/International Society for Heart and Lung Transplantation/Society of Critical Care Medicine/Association of Organ and Procurement Organizations/United Network of Organ Sharing statement: ethical and policy considerations in organ donation after circulatory determination of death. Am J Respir Crit Care Med. 2013;188:103-9.

48. Angel LF, Levine DJ, Restrepo MI, Johnson S, Sako E, Carpenter A, et al. Impact of a lung transplantation donor-management protocol on lung donation and recipient outcomes. Am J Respir Crit Care Med. 2006;174:710-6.

49. Ware LB, Landeck M, Koyama T, Zhao Z, Singer J, Kern R, et al. A randomized trial of the effects of nebulized albuterol on pulmonary edema in brain-dead organ donors. Am J Transplant. 2014;14:621-8.

50. Mascia L, Pasero D, Slutsky AS, Arguis MJ, Berardino M, Grasso S, et al. Effect of a lung protective strategy for organ donors on eligibility and availability of lungs for transplantation: a randomized controlled trial. JAMA. 2010;304:2620-7.

51. Rey MM, Ware LB, Matthay MA, Bernard GR, McGuire AL, Caplan AL, et al. Informed consent in research to improve the number and quality of deceased donor organs. Crit Care Med. 2011;39:280-3.

52. National Academies of Sciences, Engineering, and Medicine. Opportunities for Organ Donor Intervention Research: Saving Lives by Improving the Quality and Quantity of Organs for Transplantation. Washington, DC: The National Academies Press; 2017.
53. Puri V, Patterson GA, Meyers BF. Single versus bilateral lung transplantation: do guidelines exist? Thorac Surg Clin. 2015;25:47-54.

54. Black MC, Trivedi J, Schumer EM, Bousamra M II, van Berkel V. Double lung transplants have significantly improved survival compared with single lung transplants in high lung allocation score patients. Ann Thorac Surg. 2014;98:1737-41.

55. Rinaldi M, Sansone F, Boffini M, El Qarra S, Solidoro P, Cavallo N, et al. Single versus double lung transplantation in pulmonary fibrosis: a debated topic. Transplant Proc. 2008;40:2010-2.

56. Weill D, Keshavjee S. Lung transplantation for emphysema: two lungs or one. J Heart Lung Transplant. 2001;20:739-42.

57. Chauhan D, Karanam AB, Merlo A, Tom Bozzay PA, Zucker MJ, Seethamraju H, et al. Post-transplant survival in idiopathic pulmonary fibrosis patients concurrently listed for single and double lung transplantation. J Heart Lung Transplant. 2016;35:657-60.

58. Schaffer JM, Singh SK, Reitz BA, Zamanian RT, Mallidi HR. Single- vs doublelung transplantation in patients with chronic obstructive pulmonary disease and idiopathic pulmonary fibrosis since the implementation of lung allocation based on medical need. JAMA. 2015;313:936-48.

59. Thabut G, Christie JD, Ravaud P, Castier Y, Dauriat G, Jebrak G, et al. Survival after bilateral versus single-lung transplantation for idiopathic pulmonary fibrosis. Ann Intern Med. 2009;151:767-74.

60. Thabut G, Christie JD, Ravaud P, Castier Y, Brugiere O, Fournier M, et al. Survival after bilateral versus single lung transplantation for patients which chronic obstructive pulmonary disease: a retrospective analysis of registry data. Lancet. 2008;371:744-51.

61. Schumer EM, Rice JD, Kistler AM, Trivedi JR, Black MC, Bousamra M II, et al. Single versus double lung retransplantation does not affect survival based on previous transplant type. Ann Thorac Surg. 2017;103:236-40.

62. Acute Respiratory Distress Syndrome Network, Brower RG, Matthay MA, Morris A, Schoenfeld D, Thompson BT, et al. Ventilation with lower tidal volumes as compared with traditional tidal volumes for acute lung injury and the acute respiratory distress syndrome. N Engl J Med. 2000;342:1301-8.

63. Currey J, Pilcher DV, Davies A, Scheinkestel C, Botti M, Bailey M, et al. Implementation of a management guideline aimed at minimizing the severity of primary graft dysfunction after lung transplant. J Thorac Cardiovasc Surg. 2010; 139:154-61.

64. Beer A, Reed RM, Bölükbas S, Budev M, Chaux G, Zamora MR, et al. Mechanical ventilation after lung transplantation. An international survey of practices and preferences. Ann Am Thorac Soc. 2014;11:546-53.

65. National Heart, Lung, and Blood Institute Acute Respiratory Distress Syndrome (ARDS) Clinical Trials Network, Wiedemann HP, Wheeler AP, Bernard GR, Thompson BT, Hayden D, et al. Comparison of two fluid-management strategies in acute lung injury. $N$ Engl J Med. 2006;354:2564-75.

66. Geube MA, Perez-Protto SE, McGrath TL, Yang D, Sessler DI, Budev MM, et al. Increased intraoperative fluid administration is associated with severe primary graft dysfunction after lung transplantation. Anesth Analg. 2016;122:1081-8.

67. Pilcher DV, Scheinkestel CD, Snell GI, Davey-Quinn A, Bailey MJ, Williams TJ. High central venous pressure is associated with prolonged mechanical ventilation and increased mortality after lung transplantation. J Thorac Cardiovasc Surg. 2005;129:912-8.

68. Girard TD, Kress JP, Fuchs BD, Thomason JW, Schweichert Pun BT, et al. Efficacy and safety of a paired sedation and ventilator weaning protocol for mechanically ventilated patients in intensive care (awakening and breathing controlled trial): a randomized controlled trial. Lancet. 2008;371:126-34.

69. King CS, Valentine V, Cattamanchi A, Franco-Palacios D, Shlobin OA, Brown AW, et al. Early postoperative management after lung transplantation: results of an international survey. Clin Transplant. 2017;31.

70. Christie JD, Bavaria JE, Palevsky HI, Litzky L, Blumenthal N, Kaiser LR, et al. Primary graft failure following lung transplantation. Chest. 1998;114:51-60.

71. Christie JD, Kotloff RM, Pochettino A, Arcasoy SM, Rosengard BR, Landis JR, et al. Clinical risk factors for primary graft failure following lung transplantation. Chest. 2003; 124:1232-41.

72. King RC, Binns OA, Rodriguez F, Kanithanon RC, Daniel TM, Spotnitz WD, et al. Reperfusion injury significantly impacts clinical outcome after pulmonary transplantation. Ann Thorac Surg. 2000;69:1681-5.

73. Christie JD, Kotloff RM, Ahya VN, Tino G, Pochettino A, Gaughan C, et al. The effect of primary graft dysfunction on survival after lung transplantation. Am J Respir Crit Care Med. 2005;171:1312-6.

74. Fiser SM, Tribble CG, Long SM, Kaza AK, Kern JA, Jones DR, et al. Ischemiareperfusion injury after lung transplantation increases risk of late bronchiolitis obliterans syndrome. Ann Thorac Surg. 2002;73:1041-7. 
75. Daud SA, Yusen RD, Meyers BF, Chakinala MM, Walter MJ, Aloush AA, et al. Impact of immediate primary lung allograft dysfunction on bronchiolitis obliterans syndrome. Am J Respir Crit Care Med. 2007;175:507-13.

76. Diamond JM, Lee JC, Kawut SM, Shah RJ, Localio AR, Bellamy SL, et al. Clinical risk factors for primary graft dysfunction after lung transplantation. Am J Respir Crit Care Med. 2013;187:527-34.

77. Bharat A, Kuo E, Steward N, Aloush A, Hachem R, Trulock EP, et al. Immunological link between primary graft dysfunction and chronic lung allograft rejection. Ann Thorac Surg. 2008;86:189-95.

78. Liu Y, Liu Y, Su L, Jiang SJ. Recipient-related clinical risk factors for primary graft dysfunction after lung transplantation: a systematic review and meta-analysis. PloS One. 2014;9:e92773.

79. Christie JD, Sager JS, Kimmel SE, Ahya VN, Gaughan C, Blumenthal NP, et al. Impact of primary graft failure on outcomes following lung transplantation. Chest. 2005;127:161-5.

80. de Perrot M, Liu M, Waddell TK, Keshavjee S. Ischemia-reperfusion-induced lung injury. Am J Respir Crit Care Med. 2003;167:490-511.

81. Lederer DJ, Kawut SM, Wickersham N, Winterbottom C, Bhorade S, Palmer SM, et al. Obesity and primary graft dysfunction after lung transplantation: the lung transplant outcomes group obesity study. Am J Respir Crit Care Med. 2011; 184:1055-61.

82. Porteous MK, Diamond JM, Christie JD. Primary graft dysfunction: lessons learned about the first $72 \mathrm{~h}$ after lung transplantation. Curr Opin Organ Transplant. 2015;20:506-14.
83. Cantu E, Lederer DJ, Meyer K, Milewski K, Suzuki Y, Shah RJ, et al. Gene set enrichment analysis identifies key innate immune pathways in primary graft dysfunction after lung transplantation. Am J Transplant. 2013;13:1898-904.

84. Diamond JM, Cantu E, Porteous MK, Suzuki Y, Meyer KC, Lederer DJ, et al. Peripheral blood gene expression changes associated with primary graft dysfunction after lung transplantation. Am J Transplant. 2017;17:1770-7.

85. Okada Y, Kondo T. Preservation solution for lung transplantation. Gen Thorac Cardiovasc Surg. 2009;57:635-9.

86. Keshavjee SH, Yamazaki F, Yokomise H, Cardoso PF, Mullen JB, Slutsky AS, et al. The role of dextran 40 and potassium in extended hypothermic lung preservation for transplantation. J Thorac Cardiovasc Surg. 1992;103:314-25.

87. Struber M, Wilhelmi M, Harringer W, Niedermeyer J, Anssar M, Kunsebeck A et al. Flush perfusion with low potassium dextran solution improves early graft function in clinical lung transplantation. Eur J Cardiothorac Surg. 2001;19: 190-4.

88. Strüber M, Hohlfeld JM, Kofidis T, Warnecke G, Niedermeyer J, Sommer SP et al. Surfactant function in lung transplantation after 24 hours of ischemia: advantage of retrograde flush perfusion for preservation. J Thorac Cardiovasc Surg. 2002;123:98-103.

89. Venuta F, Rendina EA, Bufi M, Della Rocca T, Costa MG, Pugliese F, et al. Preimplantation retrograde pneumoplegia in clinical lung transplantation. J Thorac Cardiovasc Surg. 1999;118:107-14.

90. Clark SC, Sudarshan CD, Dark JH. Controlled perfusion of the transplanted lung Ann Thorac Surg. 2001;71:1755-6. 